\title{
Bir Boyutlu Periyodik Kaviteler İçeren Fononik Kristaller ile Akustik Ekle-Bırak Filtresi Tasarımı
}

\author{
Ahmet BIÇER* ${ }^{*}$ \\ Burdur Mehmet Akif Ersoy Üniversitesi Gölhisar Sağlık Hizmetleri Meslek Yüksekokulu Optisyenlik \\ Programı, 15400, Gölhisar/Burdur
}

Geliş / Received: 21.11.2019, Kabul / Accepted: 19.12.2019

\begin{abstract}
$\ddot{\mathbf{O} z}$
Katı yüzeyde bir boyutta periyodik silindirik kaviteler içeren dalga kılavuzları ve halka çınlaç kullanılarak tasarlanan bir akustik ekle-bırak filtresinin hava ortamında çalışması ve performansı sayısal olarak incelenmiştir. $20 \mathrm{kHz}$ civarında çalışma hedeflendiğinde, periyodu $5.0 \mathrm{~mm}$ olan $2.0 \mathrm{~mm}$ yarıçaplı kaviteler yüzeye merkezlerinden itibaren yarıçapın \%30’u kadar gömüldügünde, Sonlu Elemanlar Yöntemi kullanılarak yapılan band yapısı hesaplamaları sonucunda hedef çalışma frekansını kapsayan geniş dispersiyon sergileyen yüzey bandı belirlenmiştir. Kaviteye ve komşuluğundaki dar bir hava bölgesine lokalize olan etkileşimli Bloch yüzey akustik dalgaları, birbirine bakan ve periyodun 1.5 katı uzaklıkta iki yüzey için birbirinden ayrışan ve belirli bir frekans aralığında örtüşen iki adet yüzey bandındaki simetrik ve asimetrik kipler halini almaktadır. Dalga kılavuzları arasına her bir kılavuz ile mesafesi 1.5 periyot olan ve toplam 85 kavite içeren $67.6 \mathrm{~mm}$ yarıçaplı dairesel halka çınlaç konulduğunda, frekansa bağlı Sonlu Elemanlar Yöntemi simülasyonları ile 20 $\mathrm{kHz}$ frekansında bırak portu çıkışında maksimum gözlenirken, direkt ve ekle portlarından minimum çıkış belirlenmiştir. Port çıkışları frekansa bağlı olarak dalgalı seyir izlemekte ve gözlenen pikler artan frekans ile sıklaşmaktadır. $22.08 \mathrm{kHz}$ frekansında bırak portu çıkışında genişliği $57 \mathrm{~Hz}$ ve kalite faktörü 387 olan pik gözlenmektedir. Önerilen akustik ekle-bırak filtresi akustik sinyal işleme, akustik mantık ve ultrasonik sensörler gibi alanlarda kullanılabilir.
\end{abstract}

Anahtar Kelimeler: Yüzey akustik dalgaları, halka çınlaç, ekle-bırak filtresi, kip eşleşmesi, vuru, Sonlu Elemanlar Yöntemi.

\section{Acoustic Add-Drop Filter Design With Phononic Crystals Containing One-Dimensional Periodic Cavities}

\begin{abstract}
Operation and performance of an acoustic add-drop filter which incorporates one-dimensional cylindrical periodic cavities on a solid surface in air environment are numerically investigated. In case of $20 \mathrm{kHz}$ target operation frequency, a surface band covering this frequency with broad dispersion is determined through band structure calculations via the Finite-Element Method when cavities with $5.0 \mathrm{~mm}$ period and $2.0 \mathrm{~mm}$ radii are embedded into the surface by $30 \%$ from their centers. Interacting Bloch surface acoustic waves localized in the cavity and neighboring narrow air region become symmetric and asymmetric modes of two distinct surface bands overlapping in a particular frequency range for two facing surfaces 1.5 periods apart. When a circular ring resonator with $67.6 \mathrm{~mm}$ radius, incorporating 85 cavities, is placed between the waveguides so that it is 1.5 period away from each, frequency-domain Finite-Element simulations at $20 \mathrm{kHz}$ reveal that drop port output maximum is observed, whereas through and add outputs are minimum. Port outputs exhibit a fluctuating behavior where the observed peaks appear more frequently with increasing frequency. A peak of the drop port with $57 \mathrm{~Hz}$ width and a quality factor of 387 is observed at $22.08 \mathrm{kHz}$. The proposed acoustic add-drop filter can be utilized in areas such as acoustic signal processing, acoustic logic and ultrasonic sensors.
\end{abstract}


Keywords: Surface acoustic waves, ring resonator, add-drop filter, mode coupling, beat, Finite Element Method.

\section{Giriş}

Akustik dalgaların düzlemsel bölgelere hapsedildiği ve yönlendirildiği iki boyutlu (2B) yapay malzemeler son y1llarda yoğun ilgi çekmektedir. Bunun için, fononik kristaller olarak adlandırılan periyodik yapılar kullanılmaktadır (Khelif vd., 2006). Örneğin, ince bir levhaya bal peteği örgü düzeninde açılan silindirik deliklerden oluşan $2 \mathrm{~B}$ fononik kristal grafende olduğu gibi band yapisında Dirac konisi sergilemektedir (Torrent ve Sánchez-Dehesa, 2012). Ayrıca, kare örgü düzeninde küresel kaviteler içeren fononik kristal ile yüzey akustik dalgalarının (YAD) kendiliğinden yönelme ile kılavuzlanması gösterilmiştir (Korozlu vd., 2019). 2B YAD kontrolü düzlemsel akustik alanında geniş uygulama potansiyeline sahiptir.

Yukarıda bahsedilen YAD kipleri değişik şekillerde elde edilebilmektedir. Örneğin, bir katı yüzeyine açılan bir boyutlu (1B) oyuklar ile bu tür dalgalar elde edilebilmektedir (Christensen vd., 2007; Christensen vd., 2010; Cui vd., 2017; He vd., 2011; Jia vd., 2014; Kelders vd., 1998; Lu vd., 2015; Zhou vd., 2010; Zhu vd., 2013). Bunun yanı sira, yüzeylere açılan kare prizma veya silindirik kesitli 2B kaviteler de YAD elde edilmesi için kullanılmaktadır (Jia vd., 2013; Schwan vd., 2017; Xie vd., 2018; Ye vd., 2013). 1B ve 2B fononik kristaller ile elde edilen YAD kiplerinde akustik basınç dağılımı ve bu kiplerin dispersiyon davranışları temel olarak yüzeydeki girintilerin veya kavitelerin geometrik parametrelerine bağlıdır ( $\mathrm{Lu}$ vd., 2015).

Ekle-bırak filtreleri çınlanım için merkezlerinde bir halka çınlaç ve dalgaların bu çınlaca veya çınlaçtan kendilerine eşleştiği paralel dalga kılavuzları içeren yapılardır (Yaffe vd., 1994). Bu filtreler dalgaların kılavuzlar ile çınlaç arasında enerji değişimi ve çınlaç rezonansı birbirinden ayrı dar frekans aralıklarında gözlendiğinden, özellikle nanofotonik alanında ortamdaki kırılma indisindeki değişimlere duyarlı optik sensörlerin geliştirilmesinde kullanılmaktadır (Mai vd., 2011; Sarkaleh vd., 2017). Optik ekle-bırak filtreleri 2B fotonik kristaller ile de elde edilebilmektedir (Qiang vd., 2007). Akustik alanında ise ekle-bırak filtreleri kendilerine henüz kısıtlı yer bulabilmiştir. Örneğin, Rostami-Dogolsara vd. (2017) hava ortamında periyodik silindirik çubuklardan oluşan 2B fononik kristaller ile gerçekleştirilen ekle-bırak filtresini sayısal olarak incelemişlerdir. Ancak, deneysel olarak gerçekleştirilmiş bir akustik ekle-bırak filtresi mevcut değildir.

Bu çalışmada katı yüzeyinde 1B periyodik kaviteler içeren fononik kristallere dayalı olarak akustik ekle-bırak filtresi tasarımı sayısal olarak incelenmiştir. Ekle-bırak filtresi 1B fononik kristal YAD kipleri için doğrusal iki dalga kılavuzu ve bunlar arasında dairesel halka çınlaçtan oluşmaktadır. 1B fononik kristalin ve etkileşimli yüzeylerin band analizleri detaylı olarak yapılmıştır. Eklebırak filtresinin çıkış portlarında akustik alan dağılımı çınlaç yarıçapına ve frekansa bağlı 
olarak incelenmiştir. Bırak portunda yüksek kalite faktörüne sahip çıkış piki gözlenmesi için çalışma frekansı belirlenmiştir.

\section{Materyal ve Metot}

Çalışmada tasarlanan YAD Ekle-Bırak filtresinin şematik görünümü Şekil 1(a)'da verilmiştir. Burada merkezde $R_{\mathrm{H}}$ yarıçaplı halka çınlaç ve yüzeyi ile aralarında $d_{\mathrm{H}}$ mesafe bulunan iki adet dalga kılavuzu vardır. Çınlaç ve dalga kılavuzlarının yükseklikleri $h_{\mathrm{D}}$ ve kalınlıkları $t_{\mathrm{D}}$ olup, yüzeylerine $a$ periyot ara ile $r$ yarıçaplı ve merkezden itibaren katı içerisine $d_{\mathrm{K}}$ kadar kaydırılmış silindirik kaviteler açılmış ve $1 \mathrm{~B}$ fononik kristaller oluşturulmuştur. Dalga kılavuzlarının toplam uzunlukları $l=N . a^{\prime}$ dır. Şekil 1(a)'da alttaki dalga kılavuzunun bir tarafına $w_{\mathrm{s}}$ genişlikli bir yarık açılmıştır. Giriş $(\mathrm{G})$ portunda bu dalga k1lavuzuna gönderilen dalgalar yarık içerisinde ilerleyerek kavitelerin bulunduğu yüzeye çizgisel kaynaktan çıkan dalgalar gibi ulaşmakta ve momentum eşlenimi sayesinde dalga k1lavuzunun YAD kiplerini uyararak yüzeyde ilerleyen dalgalar oluşturmaktadır (Cicek vd., 2019). 1B fononik kristalde periyodik kavite tasarımına, $d_{\mathrm{H}}$ ve $R_{\mathrm{H}}$ değerlerine bağlı olarak, alttaki dalga kılavuzunda ilerleyen dalgalar belirli frekanslarda halka çınlaca eşleşerek çınlaç yüzeyinde ilerleyen dalgalar oluşturmaktadır. $\mathrm{Bu}$ dalgalar, frekansa bağlı olarak alttaki dalga kilavuzunun Direkt (D) olarak adlandırılan portundan ve/veya üstteki dalga kılavuzunun Ekle (E) ve Bırak (B) portlarından değişen oranlarda çıkış yapmaktadır. Akustik enerjinin çıkış portları arasındaki dağılımı ekle-bırak filtresinin geometrik tasarımına bağlı olarak kılavuzçınlaç eşlenim ve/veya halka çınlaç rezonanslarının uyarılmaları neticesinde değişmektedir.

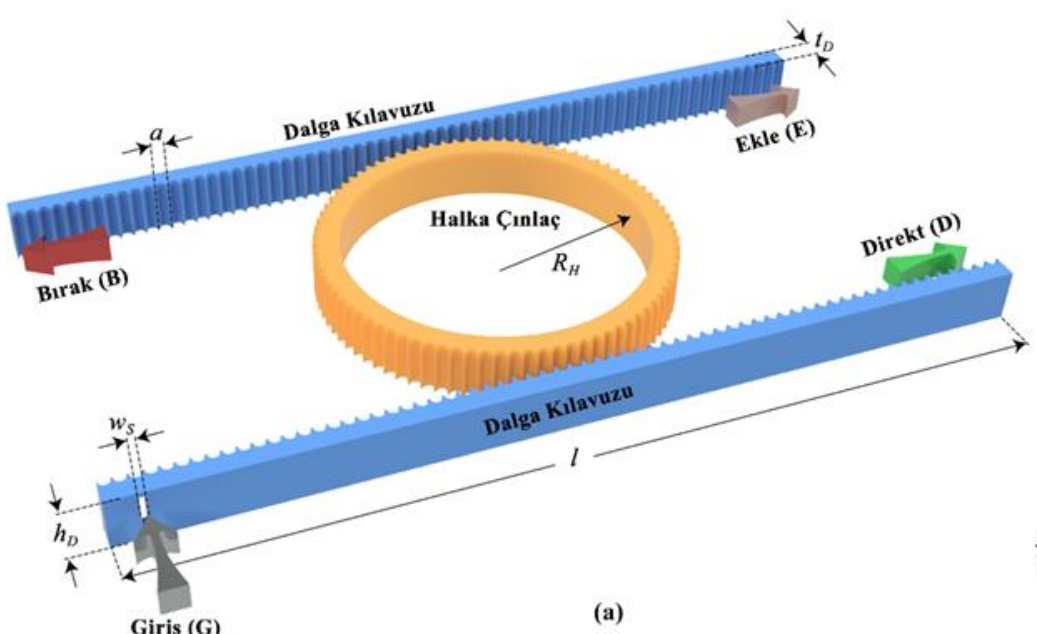

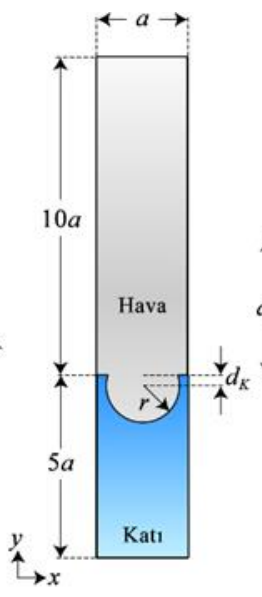

(b)

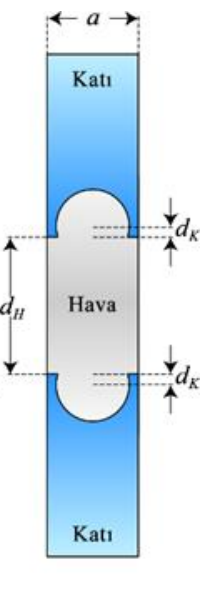

(c)

Şekil 1: (a) Tasarlanan YAD ekle-bırak filtresinin şematik gösterimi, (b) 1B fononik kristalin band yapısını ve (c) eşlenimli yüzey kiplerini belirlemede kullanılan 2B hesaplama modeli.

Ekle-bırak filtresinde akustik enerjinin çıkış portları arasındaki dağılımı dalga kılavuzları ile halka çınlaç arasında eşlenim oluşup oluşmamasına ve halka çınlaçta uygun frekanslarda rezonans koşulunun sağlanmasına bağlı olarak değişmektedir. Dalga kılavuzundan halka çınlaca eşlenimin sağlanmadiğ 1 frekanslarda alttaki kılavuzdan çıkan dalga bu kılavuz yüzeyinde ilerleyerek tamamen Direkt (D) portundan çıkmaktadır. Buna karşın, kılavuz-çınlaç eşlenimin sağlandığı ancak halka çınlaçla rezonans koşulunu sağlamadığ 1 frekanslarda ilerleyen dalgalar 
çınlaç yüzeyinde yarım tur ilerleyerek kismen Ekle (E) kismen de Birak (B) portundan sistemi terk etmektedir. Son olarak, hem eşlenim hem de çınlaç rezonans koşullarının sağlandığı frekanslarda dalgalar çınlaçta bir tam tur ilerleyerek sistemi yine ağırlıklı olarak D portundan terk etmektedir. Böylelikle çalışma frekansı değiştirilerek ekle-bırak filtresinde portlardan çıkış oranları ayarlanabilmektedir. Sistemde iki farklı rezonans koşulu bulunduğundan bireysel port çıkışları frekansa bağlı olarak keskin pikler şeklinde gözlenmektedir.

Ekle-bırak filtresi tasarımında 1B fononik kristal YAD kiplerinin belirlenmesi için Sonlu Elemanlar Yöntemine (FiniteElement-Method, FEM) dayalı band yapıs1 (dalga vektörü-frekans öz değerleri) simülasyonları yapılmıştır. Bunun için, COMSOL Multiphysics yazılımının akustik modülü kullanılmıştır. Hesaplamalarda iki boyutlu (2B) hesaplama modelleri kullanılmıştır. Örneğin, eşlenimli yüzeylerin band yapısı hesaplarında Şekil 1(b)'deki hesaplama modeli kullanılmıştır. Burada, hava ile katı arasında akustik empedans farkı çok büyük olduğundan, hava-katı ara kesitleri sonsuz rijit (sound hard) sınır koşulu ile tanımlanmıştır. Bunun için, COMSOL Multiphysics akustik modülü ile hesaplamalarda yalnızca Şekil 1(b) ve (c)'deki hava içeren bölgeler dikkate alınmıştır. Periyodik birim hücrenin düşey sınırları birbirlerine Bloch-Floquet periyodik sınır koşulları ile ilişkilendirilmiştir. Bütün hesaplamalarda hava yoğunluğu $r=1.21 \mathrm{~kg} / \mathrm{m}^{3}$ ve havada ses hızı $c_{\mathrm{a}}=343 \mathrm{~m} / \mathrm{s}$ alınmıştır. Tek bir fononik kristalin band yapısı hesaplarında kavite üzerinde $10 a$ kalınlığında hava katmanı dikkate alınmıştır. Tasarlanan ekle-bırak filtrelerinin performansları frekansa bağlı FEM simülasyonları ile incelenmiştir.

Şekil 1 (b)'de 1B fononik kristal band yapıs1 hesaplamada kullanılan birim hücre görülmektedir. Burada katı ve hava katman kalınlıkları sırasıyla $5 a$ ve $10 a$ alınmıştır. $x$ eksenine dik kenarlar periyodik sınır koşulu ile ilişkilendirilmiştir. Şekil 1 (c)'de ise eşlenimli iki fononik kristalin band yapısı hesabında kullanılan hesaplama modeli görülmektedir. Birim hücre genişliği yine $a$ iken, kavite yüzeyleri arasındaki mesafe de $d_{\mathrm{H}}$ olarak seçilmiştir. Etkileşimli YAD bandlarının dispersiyon eğrilerinin $d_{\mathrm{H}}$ 'a bağlı değişimi incelenmiştir.

\section{Bulgular}

Çalışmada $20 \mathrm{kHz}$ civarındaki frekanslarda çalışan ekle-bırak filtreleri elde etmek için $a=5.0 \mathrm{~mm}$ alınmıştır. Ayrıca, $r / a$ oranının 0.5 'e yaklaştığı kavite yarıçapları $(r)$ için birbirleri ile etkileşen ilerleyen Bloch kipleri elde edilirken, küçük yarıçaplarda birbirlerinden görece yalıtılmış durağan kipler elde edilmektedir (Korozlu vd., 2019). Bu nedenle, hesaplamalarda $r=0.4 a$ olarak sabitlenmiştir. Çalışmada hem kaviteler içerisine yeterince lokalize olan hem de güçlü etkileşip geniş dispersiyona sahip YAD kip bandlarının elde edilmesini sağlayan $d_{\mathrm{K}}=0.3 r$ değeri seçilmiştir.

$a=5.0 \mathrm{~mm}$ ve $r=0.4 a=2.0 \mathrm{~mm}$ olacak biçimde periyodik silindirik kaviteler içeren 1B fononik kristal band yapısının $d_{\mathrm{K}}$ ile değişimi Şekil 2(a)'da verilmiştir. Band hesabında yüzeye paralel dalga vektörü büyüklüğü $\left(k_{\mathrm{x}}\right)[0, \pi / a]$ arağında 50 adımda taranarak her bir $k_{\mathrm{x}}$ değeri için frekans öz değerleri belirlenmiş ve $k_{\mathrm{x}}$ 'e bağlı olarak değişimleri çizilmiştir, Şekil 2(a). Burada, çapraz katı siyah çizgi hava ortamında akustik dalgaların $\omega=c_{\mathrm{a}} k_{\mathrm{x}}$ biçiminde 
tanımlanan dispersiyon eğrisidir ve Hava Çizgisi olarak adlandırılmıştır. Bu çizginin önemi kavitelere lokalize olan Bloch kipleri ile hava ortamında yığın (Bulk) dalga olarak ilerleyen kipleri birbirinden ayırmasıdır (Khelif vd., 2006; Korozlu vd., 2019). Bu çizginin üzerindeki kipler dikkate alınmamış olup, bu bölge gri renkli taranmıştır.

Şekil 2(a)' da $-0.3 r \leq d_{\mathrm{K}} \leq 0.9 r$ aralığında $0.1 r$ adımlarla artırılan tüm $d_{\mathrm{K}}$ değerlerinde hava çizgisinin altında yalnızca bir YAD bandı gözlenmektedir. Bundan sonra yüzey bandı olarak bahsedilecek olan bu bandin dispersiyon eğrisi, hava çizgisine çok yakın seyretmekte, hava çizgisinden ancak $k_{\mathrm{x}} \sim \pi / a$ değerlerinde ayrışmaktadır. Bir başka deyişle, kavitelerin yüzeye merkezlerine kadar gömülmediği $d_{\mathrm{K}}<0$ olan durumlarda yüzeye zayıf bağlı Bloch YAD kipleri elde edilmektedir (Korozlu vd., 2019). Bu kiplerde akustik alan hava bölgesine doğru birkaç örgü sabiti boyunca genişleyebilmektedir. Öte yandan, yüzey band $1 d_{\mathrm{K}}$ büyüdükçe daha geniş bir $k_{\mathrm{x}}$ aralığında hava çizgisinden ayrışmakta ve maksimum frekans değeri aşağıya kaymaktadır. Şekil 2(a)'da $d_{\mathrm{K}}=0.9 r$ için yüzey bandının $k_{\mathrm{x}}>0.6 \pi / a$ aralığında düzleştiği ve dispersiyonunun azaldığ 1 görülmektedir. Bunun nedeni, $d_{\mathrm{K}} \sim r$ olan durumlarda kavitelerin hemen hemen tamamı yüzeye gömüldüğünden zayıf etkileşimli lokalize Helmholtz rezonatör durumları elde edilmesidir (Korozlu vd., 2019). Ayrıca, $d_{\mathrm{K}}>0.5 r$ için yüzey bandının maksimum frekansı referans frekansı olan $20 \mathrm{kHz}$ 'in altında kalmaktadır. Yukarıda anılan nedenlerle Şekil 2(a)'da kalın kırmızı çizgi ile gösterilen $d_{\mathrm{K}}=0.3 r$ tercih edilmiştir.

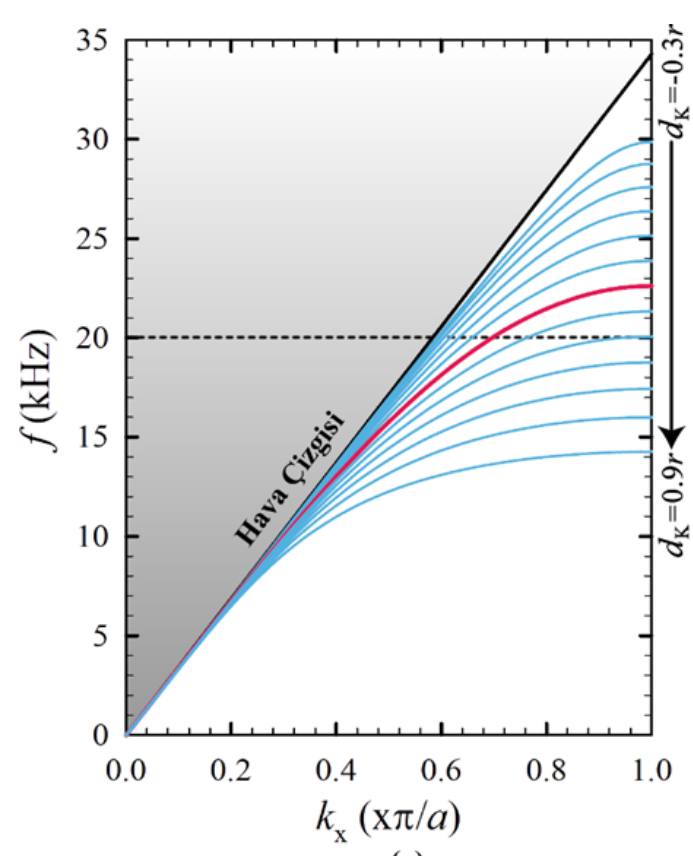

(a)

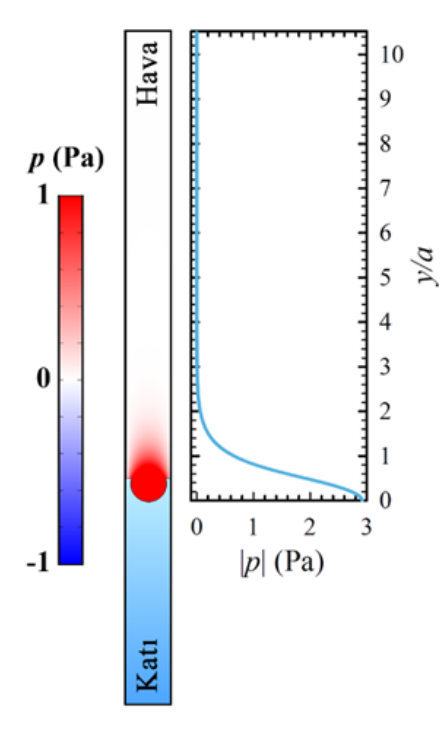

(b) (c)

Şekil 2: (a) 1B fononik kristal yüzey için yüzey kip bandının kavite gömülme oranıyla $\left(d_{\mathrm{K}}\right)$ değişimi, (b) $d_{\mathrm{K}}=0.3 r$ için $k_{\mathrm{x}}=\pi / a$ noktasındaki kip profili ve (c) yüzey kipinde akustik basıncın düşey doğrultuda değişimi.

$a=5.0 \mathrm{~mm}, r=0.4 a=2.0 \mathrm{~mm}$ ve $d_{\mathrm{K}}=0.3 r=0.6$ $\mathrm{mm}$ olacak biçimde 1B periyodik kaviteler içeren yüzeyde $k_{\mathrm{x}}=\pi / a$ noktasında Bloch YAD kipi şekillenimi Şekil 2(b)'de 
verilmiştir. Burada, akustik alanın kavite içerisinde ve etrafinda yoğunlaştı̆̆ ve akustik basıncın kaviteden uzaklaştıkça hızla azalıp sıfıra düştüğü görülmektedir. Bir başka deyişle, yukarıdaki parametreler için hem kavitelere lokalize olmuş hem de yeterince geniş bir aralıkta dispersiyon sergileyen $\quad$ YAD kipleri elde edilebilmektedir. Şekil 2(c)'de Şekil 2(b)'deki YAD kipinde akustik basincin mutlak değerinin $(|p|)$ düşey doğrultuda değişimi görülmektedir. Burada basınç kavite tabanında $(y=0)$ maksimum iken, düşey doğrultuda üstel olarak azalmaktadır. Ayrıca, basıncın kavite tavanından yaklaşık $a$ kadar uzaklıkta yarıya düştüğü görülmektedir, Şekil 2(c).

Yukarıdaki geometrik parametreler kullanılarak Şekil 1(b)'deki birbirinden $d_{\mathrm{H}}$ kadar ayrı etkileşimli yüzeyler için band yapısının $d_{\mathrm{H}}$ ile değişimi Şekil 3(a)'da verilmiştir. $d_{\mathrm{H}}=2.0 a$ için (en sağdaki grafik) Şekil 2(a)'dan farklı olarak iki adet yüzey band1 görülmektedir. $\mathrm{Bu}$ bandlar, $d_{\mathrm{H}}>>a$ için birbirine yaklaşarak pratik olarak etkileşimsiz iki bağımsız yüzeyin Şekil 2(a)'daki gibi yüzey bandına dönüşen iki katlı çakışık tek banda indirgenmektedir. Öte yandan, $d_{\mathrm{H}}$ azaldıkça (Şekil 3(a)'da sola doğru gidildikçe) çakışıklık belirgin şekilde ortadan kalkmakta ve iki yüzey band 1 birbirinden uzaklaşmaktadır. Örneğin, $d_{\mathrm{H}}=0.5 a$ için tamamen $20 \mathrm{kHz}$ 'in üzerindeki frekanslarda zayıf dispersiyon sergileyen bir band (kırmızı çizgi) ile $20 \mathrm{kHz}$ 'in altındaki frekanslarda daha geniş dispersiyon sergileyen başka bir band (mavi çizgi) gözlenmektedir, Şekil 3(a). Bu iki band $d_{\mathrm{H}}=1.0 \mathrm{a}$ için birbirine yaklaşsalar da hiçbir $k_{\mathrm{x}}$ değerinde örtüşmemektedir. Buna karşın, bandlar $d_{\mathrm{H}} \geq 1.5 a$ değerlerinde 20 kHz'i kapsayacak biçimde birbirleri ile örtüşmektedir. Bandlarda gözlenen bu örtüşme birbirlerine paralel yüzeylerde YAD kiplerinin yüzeyler arasında vuru sergileyecek biçimde transferi için önemlidir (Cicek vd., 2019). Burada vuru kavramı paralel iki adet $1 \mathrm{~B}$ fononik kristalde akustik enerjinin bir kristalden diğerine ve sonra yine başlanğıçtaki kristale aktarılması için gerekli mesafeyi ifade etmektedir. Belirli bir $f$ frekansında vuru periyodu, $L_{V}=2 \pi / \Delta k_{\mathrm{x}}$ olmaktadır (Cicek vd., 2019). Örneğin $f=20 \mathrm{kHz}$ 'te Şekil 3(a)' da üstteki ve alttaki yüzey bandları örtüşürken, $\Delta k=k_{2}-k_{1}=0.18 \pi / a$ olup, vuru periyodu $L_{\mathrm{V}}=11.1 a$ değerini alır ve $d_{\mathrm{H}}=1.5 a$ kadar birbirinden uzakta iki yüzey arasında akustik enerji transferinin bir tam çevirimi bu mesafede gerçekleşir. $d_{\mathrm{H}}=1.5 a$ için $f=20$ $\mathrm{kHz}$ de hesaplanan $L_{\mathrm{v}}=11.1 \mathrm{a}$ değeri dalga kılavuzları ile halka çınlaç arasındaki minumum mesafe konumla değiştiğinden kılavuz-çınlaç arasında tam eşlenim sağlanması için yeterli bir mesafedir. Şekil 3(a)'da frekans $f>20 \mathrm{kHz}$ olacak biçimde arttırıldıkça $\Delta k$ yaklaşık $21 \mathrm{kHz}$ 'e kadar azalmakta, $21 \mathrm{kHz}-22.5 \mathrm{kHz}$ aralığında ise artmaktadır ve dolayısıyla bu aralıkta $L_{\mathrm{V}}$ azalmaktadır. $\mathrm{Bu}$ nedenle, $21 \mathrm{kHz}$ ten büyük frekanslarda Şekil 1(a)'daki eklebırak filtresinde dalga kılavuzları ile halka çınlaç arasındaki etkin enerji transferi daha kısa mesafelerde gerçekleşmektedir. 

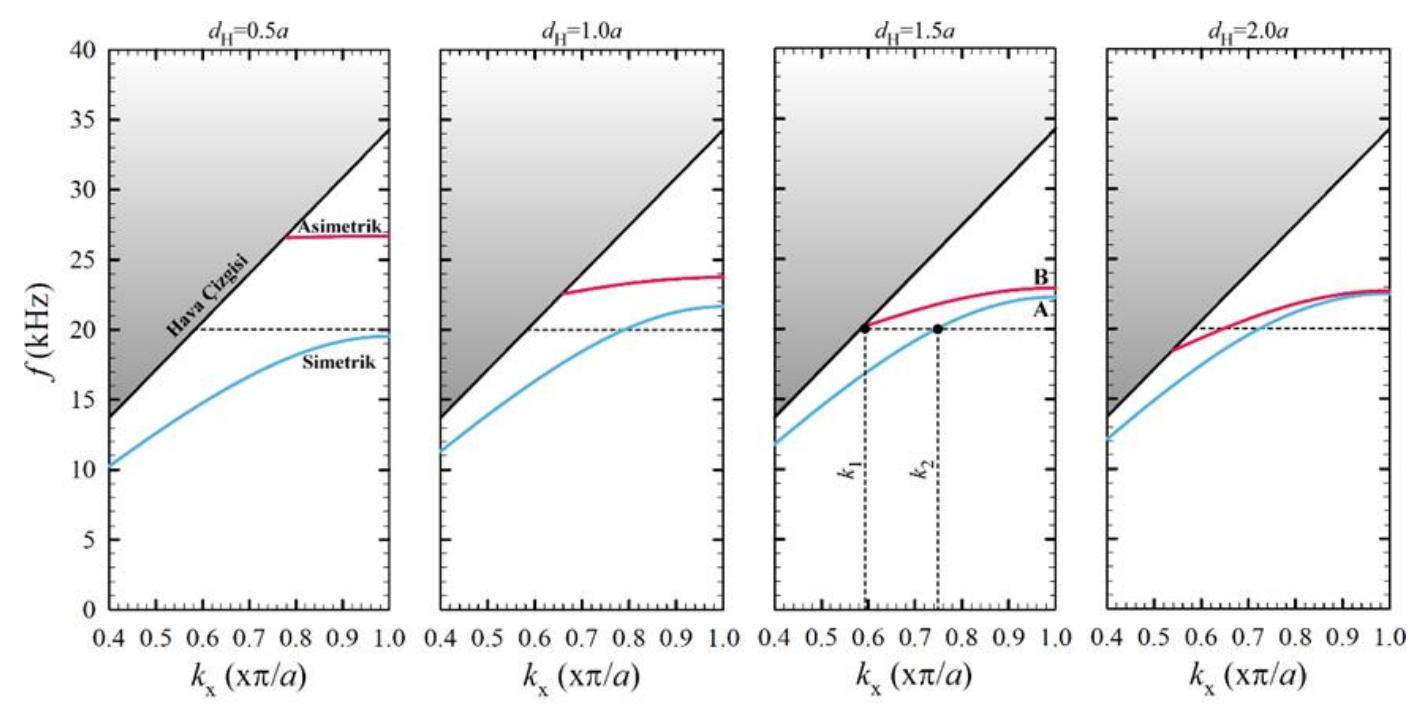

(a)

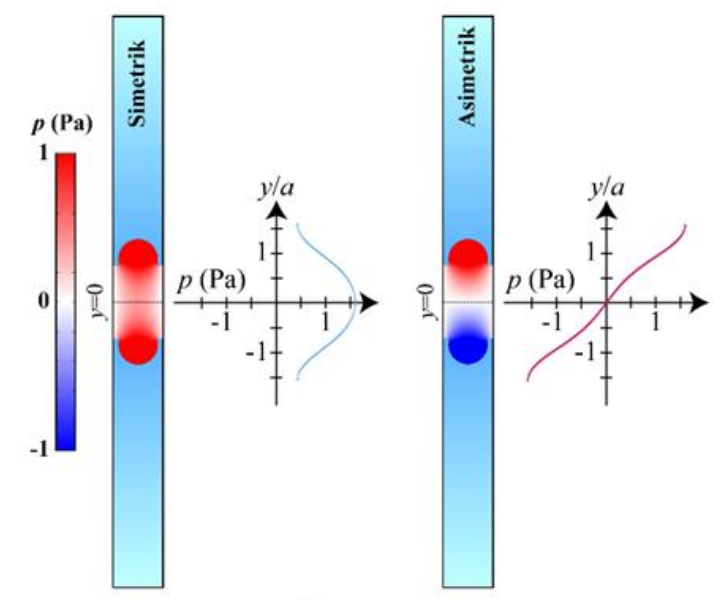

(b)

Şekil 3: (a) Eşlenimli yüzeylerde simetrik ve asimetrik yüzey kiplerini içeren bandların yüzeyler arasındaki mesafe $\left(d_{\mathrm{H}}\right)$ ile değişimi, (b) $d_{\mathrm{H}}=1.5 a$ ve $d_{\mathrm{K}}=0.3 r$ için $k_{\mathrm{x}}=\pi / a$ noktasında simetrik (sol) ve asimetrik (sağ) yüzey kip şekillenimleri. (b)'de sağdaki grafikler düşey doğrultuda basınç değişimini göstermektedir.

Şekil 3(a)'da mavi ve kırmızı renkli yüzey bandları sirasiyla simetrik ve asimetrik bandlar olarak isimlendirilmiştir. Bunun nedeni, Şekil 3(b)'de $d_{\mathrm{H}}=1.5 a$ için Şekil 3(a)'daki band yapisinda A ve B noktalarında kip şekillenimleri incelendiğinde anlaşılmaktadır. Sol tarafta A noktasında simetrik banddaki etkileşimli yüzey kipinin $y=0$ doğrusuna göre simetrik olduğu ancak, B noktasındaki kipin bu doğruya göre asimetrik olduğu görülmektedir, Şekil 3(b). Bu durum, Şekil 3(b)'de 2B basınç dağılım grafiklerinin yanında verilen $y$ ekseni boyunca akustik basınç değişim grafiklerinde de açıkça görülmektedir. Etkileşimli yüzeylerde birbirlerinden $\Delta k$ kadar ayrı bu kipler arasında enerji transferi gerçekleşmektedir.

Ekle-bırak filtresi tasarımında birbirinden izole etkileşimli yüzeylerin tasarımından sonra, iki dalga kılavuzu ve halka çınlaçtan oluşan filtre tasarımına geçilmiştir. Burada, kılavuz ve çınlaç yükseklikleri ve genişlikleri $h_{\mathrm{D}}=t_{\mathrm{D}}=2 a=10.0 \mathrm{~mm}$ alınmıştır. Giriş dalgasının ilerlediği yarık genişliği ise $w_{\mathrm{S}}=0.5 a=2.5 \mathrm{~mm}$ alınmıştır. Ayrıca, k1lavuzların uzunlukları $l=66 a=33 \mathrm{~cm}$ olarak belirlenmiştir. Kılavuzlar ile halka çınlaç arasında $d_{\mathrm{H}}=1.5 a=7.5 \mathrm{~mm}$ mesafe 
bulunmaktadır. Şekil 4(a)' da $f=20 \mathrm{kHz}$ frekansında D, E, B portlarında akustik basıncın mutlak değerinin ortalaması alınarak elde edilen $|p|$ değerlerinin halka çınlaçtaki kavite sayısı $\left(N_{\mathrm{D}}\right)$ ile değişimi görülmektedir. Her üç portta $N_{\mathrm{D}}$ ile dalgalı değişen çıkış gözlenmektedir. Genel olarak, D portunda çıkış minimum iken B portunda maksimumdur, Şekil 4(a). E portu çıkışındaki dalgalanmalar ise $\mathrm{B}$ portu çıkışına benzer seyir izlemektedir. B portundan çıkış düzeyi baz alındığında, $N_{\mathrm{D}}=85$ için $f=20 \mathrm{kHz}$ frekansında maksimum çıkış elde edilmektedir. Ayrıca, D portundan çıkışta minimum olmaktadır.

Şekil 4(a)'da düşey kesikli çizgiyle gösterilen $\quad N_{\mathrm{D}}=85$ ve yarıçapı $R_{\mathrm{H}}=N_{\mathrm{D}} a / 2 \pi=67.6 \mathrm{~mm}$ olan halka çınlaç içeren ekle-bırak filtresinin $f=20 \mathrm{kHz}$ frekansında FEM simülasyon sonucu Şekil 4(b)'de görülmektedir. Burada, yarıktan çıkan dalga alttaki dalga kılavuzunun YAD kipi ile eşleşerek yüzeyde ilerleyip, kılavuzun çınlaca en yakın olduğu bölgede çınlaca aktarılıp, son olarak da çınlaçta yarım tur döndükten sonra üstteki dalga kılavuzuna eşleşip B portundan sistemi terk etmektedir. Çınlacın dairesel yapısından dolayı, kılavuz-çınlaç mesafesi değiştiğinden, akustik enerji aktarımı kısmen gerçekleşmekte ve D ile E portlarından az da olsa çıkış gözlenmektedir. Şekil 4(b)'de hesaplama alanının sağ ve sol kenarlarında sınırları düzlem dalgalar için soğurucu sınır koşulu (COMSOL, 2019) ile tanımlanan dikdörtgensel girintiler yarıktan çıkan ve halka çınlaçtan saçılan dalgaların doğrudan portlara ulaşmasını engelleyip; portlara yalnızca k1lavuzlar üzerinde ilerleyen dalgaların erişmesini sağlamaktadır.
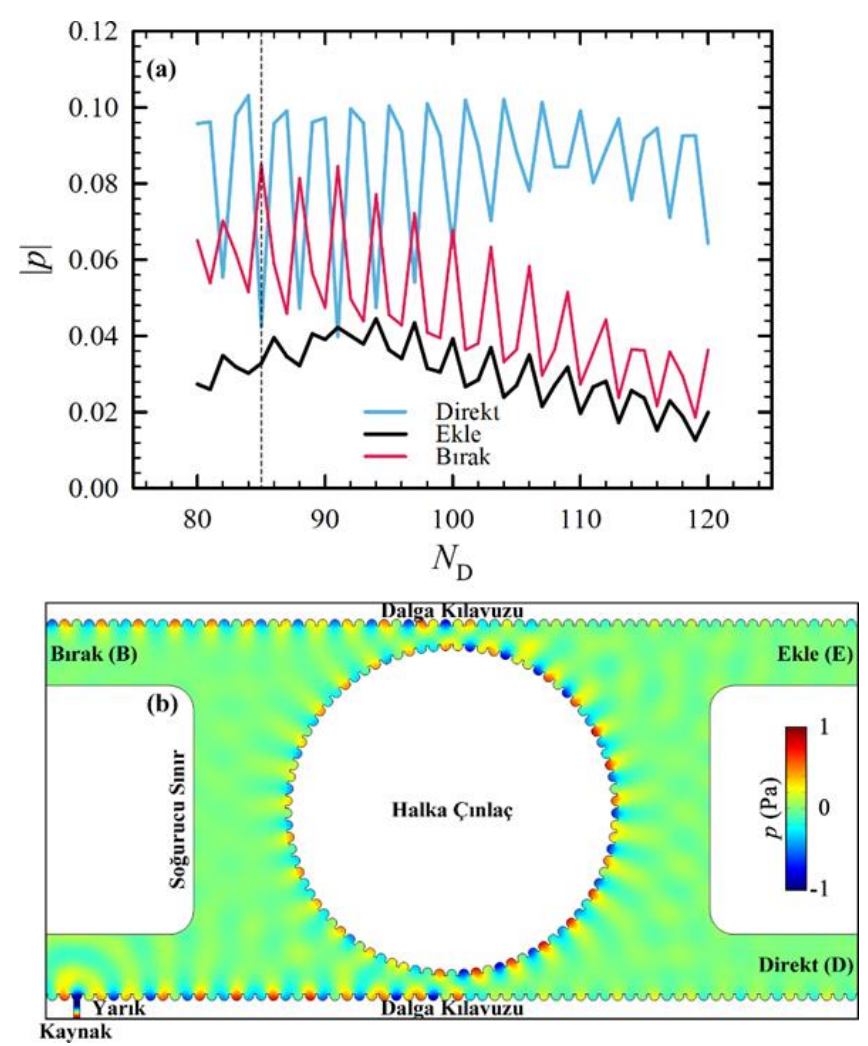

Şekil 4: (a) YAD ekle birak filtresinde $f=20.00 \mathrm{kHz}$ frekansında Direkt (D), Ekle (E) ve Bırak (B) portlarında akustik basıncın mutlak değerinin halka çınlaç yüzeyindeki kovuk sayısıyla $\left(N_{\mathrm{D}}\right)$ değişimi ve (b) $d_{\mathrm{H}}=1.5 a$ ve $d_{\mathrm{K}}=0.3 r$ için $f$ frekansında FEM simülasyon sonucu. 
Şekil 4(b)'deki simülasyon sonucunda kılavuz-çınlaç arasındaki vuru mesafesinin $\left(L_{\mathrm{V}}\right)$ yanı sıra, çınlacın rezonans frekansları da etkilidir. Burada, $R_{\mathrm{H}} k_{\mathrm{x}}=m=\operatorname{tam}$ say 1 koşulunu sağlayan frekanslarda çınlaç rezonans1 görülmektedir. Bu ifade frekansa bağlı olarak, $N_{\text {D. }}$ a.f $/ c_{\mathrm{a}}=m=$ tam sayı halini alır. Şekil 4(b)'deki halka çınlaç için bu $m$ $\in[25,30]$ aralığında $20.18 \mathrm{kHz}, 20.89 \mathrm{kHz}$, $21.79 \mathrm{kHz}, 22.60 \mathrm{kHz}, 23.41 \mathrm{kHz}$ ve 24.22 $\mathrm{kHz}$ frekanslarında rezonans gözlenmesi anlamina gelmektedir.

$N_{\mathrm{D}}=85$ olan ekle-bırak filtresinde çıkış portlarında akustik basıncın mutlak değerinin frekansla değişimi Şekil 5(a)'da verilmiştir. $20 \mathrm{kHz}$ 'in altındaki frekanslarda asimetrik bandın kipi bulunmadığından YAD yalnızca alttaki dalga k1lavuzunda ilerlemekte ve filtreyi doğrudan D portundan terk etmektedir. Ancak, simetrik ve asimetrik bandların örtüştüğü 20 kHz'in üzerindeki frekanslarda her üç port çıkışında artan frekansla sıklaşacak biçimde dalgalanmalar görülmektedir. Şekil 5(b)'de 22.0-22.4 kHz aralığında $1 \mathrm{~Hz}$ adımlarla hesaplanan port çıkışları görülmektedir. Burada, B port çıkışı maksimumken D port çıkışı minimumdur. Şekil 5(a)'da B port çıkışının maksimum olduğu $22.08 \mathrm{kHz}$ değeri işaretlenmiştir. Burada, B çıkış pikinin yarı yükseklikte tam genişliği (FWHM) $57 \mathrm{~Hz}$ olup, pik değerinin kalite faktörü $Q=387$ olarak belirlenmiştir.

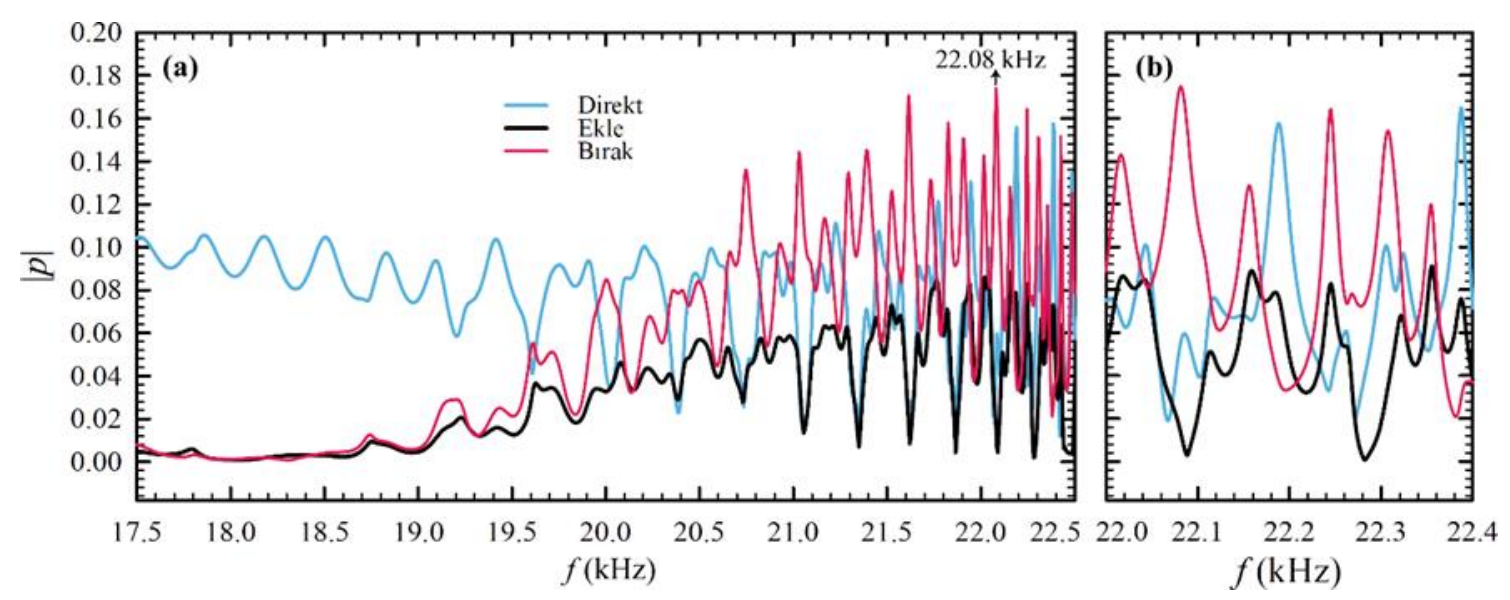

Şekil 5: (a) $N_{\mathrm{D}}=85$ olan YAD ekle-bırak filtresinde $\mathrm{D}, \mathrm{E}$ ve B portlarında akustik basıncın mutlak değerinin frekansla değişimi, (b) $22.0-22.4 \mathrm{kHz}$ aralığında yakından görünüm.

Tasarlanan ekle-bırak filtresinin farklı frekanslardaki FEM simülasyon sonuçları Şekil 6'da verilmiştir. Çalışmada, B ile D portları arasındaki kontrastın maksimum olduğu Şekil 5(a)'da ok ile gösterilen 22.08 $\mathrm{kHz}$ etrafındaki davranış dikkate alınmıştır. $20 \mathrm{kHz}$ 'te bu portlardan çıkış kontrastı düşük ve rezonans pikleri geniş olduğundan ekle-bırak filtresi performansı incelenirken bu frekans aralığı dikkate alınmamıştır. Şekil 6' da $f=22.000 \mathrm{kHz}$ frekansında her üç porttan birbirine yakın çıkış gözlenmektedir. Buna karşın, $f=22.066 \mathrm{kHz}$ frekansında D portundan çıkış minimum düzeyde iken $\mathrm{B}$ portundan çıkış baskın olarak gözlenmektedir. Şekil 6'daki B portu için pik frekansı olan $f=22.082 \mathrm{kHz}$ frekansında B portundan çıkış maksimumken diğer portlarda minimum düzeydedir. Son olarak $22.383 \mathrm{kHz}$ frekansında Şekil 6' da da görüldüğü gibi D portundan çıkış maksimumken B portundan çıkış minimumdur. 

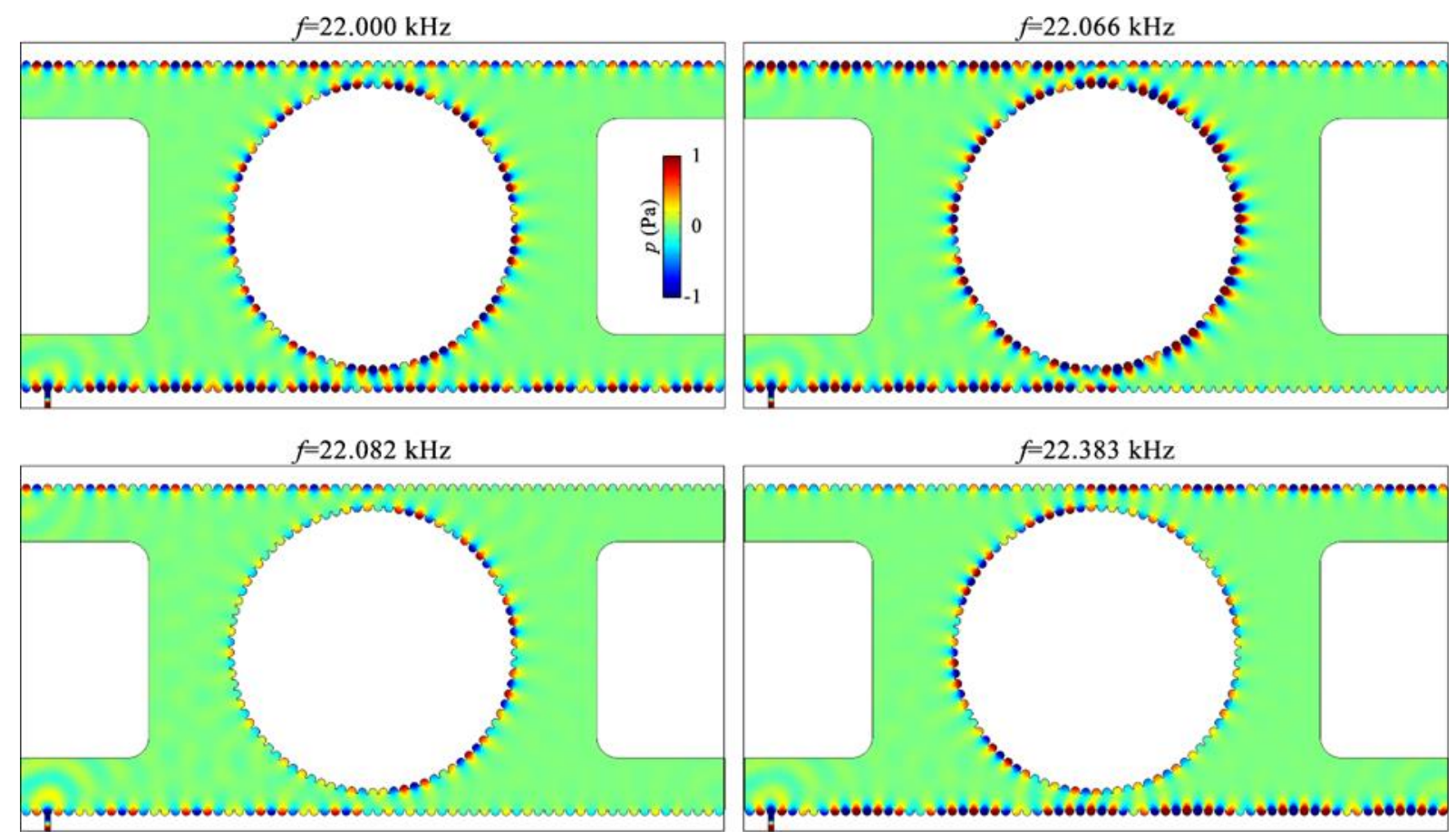

Şekil 6: $N_{\mathrm{D}}=85$ olan YAD ekle-bırak filtresinde farklı frekanslarda FEM simülasyon sonuçları.

\section{Sonuç ve Tartışma}

Sonuç olarak, katı yüzeylerde periyodik silindirik kaviteler içeren 1 boyutlu fononik kristaller kullanilarak periyot, kavite yarıçap1 ve kavitenin katı içerisine gömülme oranına bağlı olarak dispersiyon davranışları değişen yüzey akustik dalgası kiplerinin iki dalga k1lavuzu ve bir dairesel halka çınlaç içeren ekle-bırak filtresi tasarımında kullanılabileceği sayısal hesaplamalarla gösterilmiştir. Kılavuz yüzeylerinde ilerleyen ve geniş dispersiyon sergileyen yüzey kiplerinin eldesi için yarıçap/periyot oranının $1 / 2$ değerine yakın olması ve silindirik kavitelerin merkezlerinden itibaren yüzeye gömülme oranlarının 0 ile yarıçapın yarısı arasında değişmesi gerekmektedir. Örneğin bu değer $0.3 \mathrm{x}$ yarıçap olduğunda, yüzeye periyoda yakın bir uzanımda lokalize olmuş ilerleyen Bloch YAD kipleri elde edilebilmektedir.

Kaviteler içeren ve birbirine bakan iki özdeş yüzey birbirlerinden sonsuz uzaklıkta iken, tamamen örtüşen iki katlı çakışık yüzey bandları gözlenmektedir. Buna karşın, yüzeyler birbirlerine bir periyot ya da daha yakın olacak biçimde yaklaştırıldığında çakışıklık ortadan kalkarak bandlar birbirlerinden ayrılmakta ve hiçbir frekans aralığında örtüşmeyen dispersiyon sergilemektedir. Ancak, yüzeyler arasındaki mesafe periyodun bir buçuk katı olduğunda hem yüzey bandları yeterince birbirinden ayrilabilmekte hem de referans seçilen bir frekans civarında örtüşmektedir. $\mathrm{Bu}$ iki yüzey kipleri yüzeyleri ortadan ayıran doğruya göre simetrik veya asimetrik akustik basınç dağılımı sergilemektedir. Yüzeyler arasında akustik dalgalar bu kiplerin dalga vektörlerinin büyüklüklerinin farkı ile ters orantılı olarak değişen bir mesafede yüzeylerin ilerleme doğrultusundaki uzunluklarına bağlı olarak değişen sayılarda vuru gözlenecek biçimde bir yüzeyden diğerine transfer edilerek ilerlemektedir. Dalga vektörü büyüklükleri 
arasındaki fark arttığında vuru mesafesi periyotla karşılaştırılabilecek büyüklüklerde olacak biçimde ayarlanabildiğinden, uygun frekanslarda dalga kılavuzları ile dairesel halka çınlaç arasında YAD enerjisinin tamamen transferi sağlanabilmektedir.

Yüzeyinde silindirik kaviteler içeren dairesel halka çınlaç ile bu çınlaçtan $1.5 \mathrm{x}$ periyot kadar uzakta 2 dalga kılavuzu içeren ekle-birak filtresinde direkt ve birak portlarından çıkış oranları çınlaç yüzeyindeki kavite sayısına, dolayısıyla çınlaç yarıçapına, bağlı olarak değişmektedir. Örneğin, $20 \mathrm{kHz}$ frekansinda birak portundan maksimum ve direkt ile ekle portlarından minimum çıkış isteniyorsa, çınlaç yüzeyinde toplam 85 kavite bulunması gerekmektedir. Portlar arasında çıkış oranlarının dağılımları vuru mesafesinin yanı sıra, halka çınlaç rezonans frekansına da bağlıdır. Rezonans koşulu sağlandığında, yüzey akustik dalgaları çınlaçta tam tur dolanırken direkt portunda çıkış maksimum, bırak portunda ise minimum olmaktadır. Örneğin, Şekil (6)'da halka çınlaç rezonans frekanslarından biri olan $21.79 \mathrm{kHz}$ 'e yakın $22.000 \mathrm{kHz}$ ve $22.066 \mathrm{kHz}$ frekanslarında YAD halka çınlacı tam turlarken, bırak portunda pik gözlenen $22.082 \mathrm{kHz}$ frekansında yarım tur dönerek ağırlıklı olarak filtreyi bu çıkıştan terk etmektedir.

$\mathrm{Bu}$ çalışmada tasarlan akustik ekle-bırak filtresi $20 \mathrm{kHz}$ civarındaki frekanslar için optimize edilmiş olup, yaklaşık $330 \mathrm{~mm} \mathrm{x}$ $150 \mathrm{~mm}$ boyutlara sahiptir. Filtre boyutları tasarım frekansı arttırılarak düşürülebilir ve pratik uygulamalar için kompakt cihazlar elde edilebilir. Bu çalışmada yalnızca giriş portundan akustik dalga uygulanmıştır. Ancak, ekle portundan farklı frekansta dalga girişi ile çift yönlü çalışan filtre elde edilebilir. Filtre doğrusal çalıştığından, farklı frekanslardaki dalgalar birbirleri ile etkileşmeden işlenebilir. Ekle-bırak filtresi akustik sinyal işleme, akustik mantık ve ultrasonik gaz sensörleri gibi uygulamalarda kullanılabilir.

\section{Teşekkür}

Çalışmada hesaplama kaynaklarını kullanma imkanı veren Prof. Dr. Ahmet ÇİÇEK ve Doç. Dr. Nurettin KÖRÖZLÜ'ye teşekkür ederim.

\section{Kaynaklar}

Christensen, J., Fernandez-Dominguez, A. I., de Leon-Perez, F., Martin-Moreno, L., ve Garcia-Vidal, F. J. 2007. "Collimation of sound assisted by acoustic surface waves", Nature Physics 3(12), 851.

Christensen, J., Martín-Moreno, L., ve Garcia-Vidal, F. J. 2010. "Enhanced acoustical transmission and beaming effect through a single aperture", Physical Review $B, 81(17), 174104$.

Cicek, A., Arslan, Y., Trak, D., Okay, F. C., Kaya, O. A., Korozlu, N., ve Ulug, B. 2019. "Gas sensing through evanescent coupling of spoof surface acoustic waves", Sensors and Actuators B: Chemical, 288, 259-265.

COMSOL, Inc. 2019. COMSOL Multiphysics Modeling Software, URL: https://comsol.com , Son erişim tarihi: 21/11/2019.

Cui, J., Liu, J., Mao, Y., Li, Y., ve Liu, X. 2017. "Realization of manipulating acoustic surface waves radiation direction with rectangular-groove structure", AIP Advances, 7(11), 115301.

He, Z., Jia, H., Qiu, C., Ye, Y., Hao, R., Ke, M., ve Liu, Z. 2011. "Nonleaky surface acoustic waves on a textured rigid surface", Physical Review B, 83(13), 132101.

Jia, H., Lu, M., Ni, X., Bao, M., ve Li, X. 2014. "Spatial separation of spoof surface 
acoustic waves on the graded groove grating", Journal of Applied Physics, 116(12), 124504.

Jia, H., Lu, M., Wang, Q., Bao, M., ve Li, X. 2013. "Subwavelength imaging through spoof surface acoustic waves on a twodimensional structured rigid surface", Applied Physics Letters, 103(10), 103505.

Kelders, L., Allard, J. F., ve Lauriks, W. 1998. "Ultrasonic surface waves above rectangular-groove gratings", The Journal of the Acoustical Society of America, 103(5), 2730-2733.

Khelif, A., Aoubiza, B., Mohammadi, S., Adibi, A., ve Laude, V. 2006. "Complete band gaps in two-dimensional phononic crystal slabs", Physical Review E, 74(4), 046610.

Korozlu, N., Kaya, O. A., Cicek, A., ve Ulug, B. 2019. "Self-collimation and slowsound effect of spoof surface acoustic waves", Journal of Applied Physics, 125(7), 074901.

Lu, J., Qiu, C., Ke, M., ve Liu, Z. 2015. "Directional excitation of the designer surface acoustic waves", Applied Physics Letters, 106(20), 201901.

Mai, T. T., Hsiao, F. L., Lee, C., Xiang, W., Chen, C. C., ve Choi, W. K. 2011. "Optimization and comparison of photonic crystal resonators for silicon microcantilever sensors", Sensors and Actuators A: Physical, 165(1), 16-25.

Qiang, Z., Zhou, W., ve Soref, R. A. 2007. "Optical add-drop filters based on photonic crystal ring resonators", Optics Express, 15(4), 1823-1831.

Rostami-Dogolsara, B., Moravvej-Farshi, M. K., ve Nazari, F. 2016. "Acoustic adddrop filters based on phononic crystal ring resonators", Physical Review B, 93(1), 014304.

Sarkaleh, A. K., Lahijani, B. V., Saberkari, H., ve Esmaeeli, A. 2017. "Optical ring resonators: a platform for biological sensing applications", Journal of Medical Signals and Sensors, 7(3), 185.

Schwan, L., Geslain, A., Romero-García, V., ve Groby, J. P. 2017. "Complex dispersion relation of surface acoustic waves at a lossy metasurface", Applied Physics Letters, 110(5), 051902.

Torrent, D., ve Sánchez-Dehesa, J. 2012. "Acoustic analogue of graphene: observation of Dirac cones in acoustic surface waves", Physical Review Letters, 108(17), 174301.

Xie, S., Ouyang, S., He, Z., Wang, X., Deng, K., ve Zhao, H. 2018. "Bending and splitting of spoof surface acoustic waves through structured rigid surface", Results in Physics, 8, 52-56.

Yaffe, H. H., Henry, C. H., Serbin, M. R., ve Cohen, L. G. 1994. "Resonant couplers acting as add-drop filters made with silicaon-silicon waveguide technology", Journal of Lightwave Technology, 12(6), 10101014.

Ye, Y., Ke, M., Li, Y., Wang, T., ve Liu, Z. 201). "Focusing of spoof surface-acousticwaves by a gradient-index structure", Journal of Applied Physics, 114(15), 154504.

Zhou, Y., Lu, M. H., Feng, L., Ni, X., Chen, Y. F., Zhu, Y. Y., Zhu, S. N., ve Ming, N. B. 2010. "Acoustic surface evanescent wave and its dominant contribution to extraordinary acoustic transmission and collimation of sound", Physical Review Letters, 104(16), 164301.

Zhu, J., Chen, Y., Zhu, X., Garcia-Vidal, F. J., Yin, X., Zhang, W., ve Zhang, X. 2013. "Acoustic rainbow trapping", Scientific Reports, 3, 1728. 